\title{
Psychological strengths: An interpretative phenomenological analysis of Muslim women leaders
}

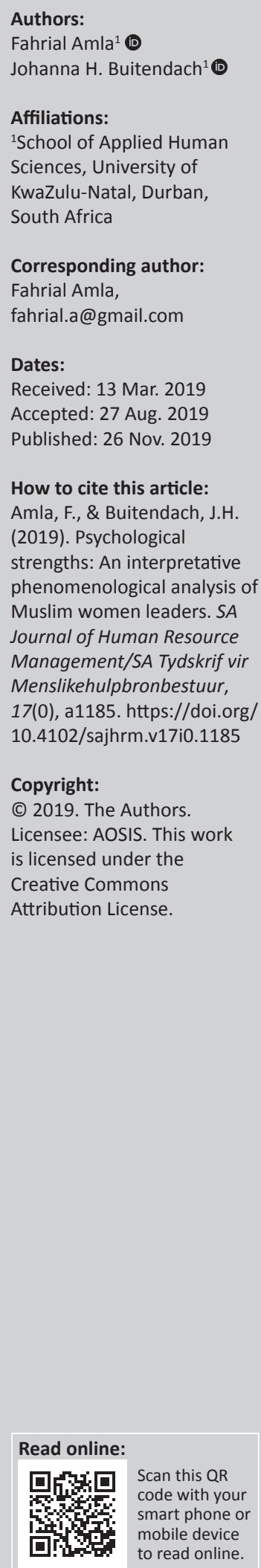

Orientation: The nature and representation of psychological strengths is an emerging area of positive psychology. Individual differences occur in strengths profiles between people, which may be attributed to educational, occupational, gender and cultural influences and can be qualitatively explored using interpretative phenomenological analysis (IPA). The application of strengths measurement is underway in South Africa, but locally developed, context-specific strengths taxonomies are currently lacking, as well as research linking psychological strengths and leadership. Muslim women in leadership deal with general gender-related leadership challenges as well as specific cultural and religious issues, and the application of psychological strengths may serve as enabling factors.

Research purpose: This study aimed to explore and describe the psychological strengths demonstrated by a minority sub-population of South African women leaders in the workplace.

Motivation for the study: Psychological strengths are linked to flourishing and well-being. Understanding their representation and their context of application can enhance both the academic literature and organisational practices surrounding them. A minority leadership group of Muslim women were appointed for this study, bearing in mind their particular leadership challenges and the enabling strengths they employ as a point of interest, as possible indicators for future strengths and leadership development initiatives.

Research approach/design and method: Qualitative, semi-structured interviews were conducted with 15 Muslim women leaders from various employment industries who held senior management or leadership roles. IPA method was used for the analysis and interpretation of the results.

Main findings: Interpretative phenomenological analysis of the interview data revealed a taxonomy of 28 psychological strengths, which were categorised as cognitive, emotional, interpersonal, values/motives or behavioural.

Practical/managerial implications: The strengths may be focussed on for leadership development and it is recommended that the study should be replicated across various cultural groups to identify and develop the strengths that occur in the diversity of leaders within the South African work context.

Contribution/value-add: This exploratory study contributes to the knowledge base of psychological strengths. It also highlights specific strengths to be considered when implementing leadership development programmes, particularly those for Muslim women in South African workplaces.

Keywords: psychological strengths; interpretative phenomenological analysis; positive psychology; leadership; women (or gender) and work.

\section{Introduction}

\section{Orientation}

Psychological strengths form one of the main branches of the field of positive psychology and constitute the characteristics that promote enabling positive thoughts, emotions and behaviours (Keenan \& Mostert, 2013). They are significantly linked to individual psychological well-being (Macaskill \& Denovan, 2014), effective and engaged leadership in organisations (Buckingham \& Clifton, 2001; Harter, Schmidt, \& Hayes, 2002) and academic achievement in postgraduate scholars (Van Der Westhuizen, De Beer, \& Bekwa, 2011).

As an emerging sub-field of positive psychology, there is significant interest in the conceptualisation, classification, measurement and development of strengths. There had initially been emphasis on 
singular or a few strength-type concepts in academic literature, such as on wisdom (Staudinger \& Leipold, 2003), empathy (Zhou, Valiente, \& Eisenberg, 2003), hardiness (Maddi, 2006) and optimism (Deptula, Cohen, Philipsen, \& Ey, 2006), to name but a few. The formalisation of the field of positive psychology since the 1998 American Psychological Association (APA) presidential address of Martin Seligman, promoted a more complete science and practice of positive psychology by enhancing well-being and happiness in addition to understanding human suffering (Seligman, Steen, Park, \& Peterson, 2005). Subsequently, assessment questionnaires and classifications were published as the StrengthsFinder by Buckingham and Clifton (2001) and the character strengths-based Values in Action Inventory of Strengths (VIA-IS) (Park, Peterson, \& Seligman, 2006). Strength-based research and practice in South Africa is a recent but growing phenomenon, primarily adopting Western developed strengths instruments. This study provides an alternate approach using the qualitative method of interpretative phenomenological analysis (IPA) to explore and derive context-specific South African based strengths with the aim of contributing to local taxonomies, bearing in mind that the environment can either constrain or enhance the development of individual psychological strengths (Stokols, 2003). The context for the exploration of strengths for this article is a minority, niche population of South African Muslim women who work within leadership capacities. The reason is that women across racial divides were socially and economically disadvantaged before the implementation of the Employment Equity Act 55 of 1998 (Department of Labour, 1998). In addition, Muslim women apparently encounter religious and cultural barriers that impact their career advancement (Ahmed, 2008). Psychological strengths serve as enablers during adversity (Goodman, Disabato, \& Kashdan, 2019) and exploring their representation at more defined samples could provide a clearer picture of the application of various strengths in work contexts.

\section{Literature review}

\section{Positive psychological strengths}

Positive psychological strengths form one of the focus areas of the field of positive psychology, which is a broad term to describe the study of positive emotion, character and institutions (Seligman \& Csikszentmihalyi, 2000; Seligman et al. 2005). Positive psychology seeks to understand what makes life worth living, contribute to improving people's lives (Seligman, 2011) and fulfil one of the original goals of the profession of psychology, which was to build human strengths and nurture genius; however, this intention became neglected by mainstream psychology because of the First and Second World Wars and subsequent focus on negative mental health (Seligman et al. 2005). According to Clifton and Harter (2003), psychological strengths have the potential to foster near-perfect performance and arise when talents are refined and applied together with knowledge and skills to yield greater positive outcomes. Strengths development was initially promoted by Buckingham and Clifton (2001) as a means to make employees happier and more engaged and enable managers to be better leaders (Kaiser \& Overfield, 2011). A study by the Corporate Leadership Council reported in the work of Biswas-Diener, Kashdan and Minhas (2011) found that performance in a group of managers increased significantly when they were given feedback on their areas of strength, while those who were informed of their weaknesses subsequently showed poorer performance. Although strengths may theoretically be easier to develop than competencies, the overuse of a strength beyond the point of performance can compromise effectiveness (Kaiser \& Overfield, 2011). Strengths application should therefore be regulated as appropriate to the situational context.

\section{Strengths measurement}

The identification of strengths may be facilitated using interviews or psychometric strengths instruments. The StrengthsFinder (Buckingham \& Clifton, 2001; Rath, 2007) assesses people's natural talents as 'signature themes'. When these talents are combined with knowledge and skill, they mature as strengths. Of the 34 strengths indicated, the highest scoring, top five measured for an individual, would be focussed on for development. The Realise 2 Strengths Profiler consists of 60 possible strengths, of which scored results are presented according to a candidate's realised and unrealised strengths, learned behaviours and weaknesses (Linley, Willars, \& Biswas-Diener, 2010). The Values in Action (VIA) strengths classification (Park et al. 2006) measures 24 'character strengths' which fall under six broad categories that represent positive character (wisdom, courage, humanity, justice, temperance and transcendence). The Strengthscope (Brook \& Brewerton, 2006) identifies 24 strengths as underlying qualities that energise an individual and can potentially be performed well at. These are categorised as emotional, relational, thinking and execution strengths, with the top seven scoring strengths being regarded as significant. Some conceptually similar or related strengths occur between these instruments - empathy on the Strengthscope and StrengthsFinder and Empathic connection on Realise2, as well as the similarity between 'creativity' on the Strengthscope, Realise 2 and VIA and 'ideation' on the StrengthsFinder. The preceding measurement instruments of strengths are mainly administered online to international candidates, but South African norms are available for the Strengthscope. The comparison of strengths measured by these instruments is presented in Figure 1.

\section{Strengths classification}

As mentioned above, variations of conceptualised strengths have been presented according to themes and categories (Aspinwall \& Staudinger, 2003; Carr, 2004; Peterson \& Seligman, 2003), but research on strengths has not yet arrived at a unitary taxonomy which clarifies the various forms and expressions of human strengths (Compton, 2005; Goodman etal.2019). Psychological strengths are generally acknowledged to be stable over time and rooted in personality. It is argued by Goodman et al. (2019) that rather than being a new concept, strengths are an adaptive expression of normal personality traits. For example, positive strength adjectives of being 


\begin{tabular}{|c|c|c|c|c|}
\hline Strength scope & Strengths finder & Realise 2 & & VIA \\
\hline Emotional & Achiever & Being & Communicating & Wisdom and knowledge \\
\hline Courage & & Authenticity & Counterpoint & Creativity \\
\hline Emotional control & Adaptability & Centred & Explainer & Curiosity \\
\hline Enthusiasm & Analytical & Courage & Feedback & Open-mindedness \\
\hline Optimism & Arranger & Curiosity & Humour & Love of learning \\
\hline Resilience & Belief & Gratitude & Listener & \\
\hline \multirow[t]{2}{*}{ Self-confidence } & Command & Humility & Narrator & - \\
\hline & Communication & Legacy & Scribe & Courage \\
\hline Relational & Competition & Mission & Spotlight & Authenticity \\
\hline Collaboration & Connectedness & Moral compass & - & Bravery \\
\hline Compassion & Consistency & Personal responsibility & Motivating & Persistence \\
\hline Developing others & Context & Pride & Action & Zest \\
\hline Empathy & Deliberative & Self-awareness & Adventure & - \\
\hline Persuasiveness & Developer & Service & Bounce back & Humanity \\
\hline Relationship building & Discipline & Unconditionality & Catalyst & Kindness \\
\hline \multirow[t]{2}{*}{ Leading } & Empathy & & Change agent & Love \\
\hline & Focus & Thinking & Competitive & Social intelligence \\
\hline Thinking & Futuristic & Adherence & Drive & - \\
\hline Common sense & Harmony & Creativity & Efficacy & Justice \\
\hline Creativity & Ideation & Detail & Growth & Fairness \\
\hline Critical thinking & Includer & Incubator & Improver & Leadership \\
\hline Detail orientation & Individualisation & Innovation & Persistence & Teamwork \\
\hline \multirow[t]{2}{*}{ Strategic mindedness } & Input & Judgement & Resilience & - \\
\hline & Intellection & Optimism & Work ethic & Temperance \\
\hline Execution & Learner & Order & - & Forgiveness \\
\hline Decisiveness & Maximiser & Planful & Relating & Modesty \\
\hline Efficiency & Positivity & Prevention & Compassion & Prudence \\
\hline Flexibility & Relator & Reconfiguration & Connector & Self-regulation \\
\hline Initiative & Responsibility & Resolver & Emotional awareness & - \\
\hline Results focus & Restorative & Strategic awareness & Empathic connection & Transcendence \\
\hline \multirow[t]{7}{*}{ Self-improvement } & Self-assurance & Time optimiser & Enabler & Appreciation of beauty and excellence \\
\hline & Significance & - & Equality & Gratitude \\
\hline & Strategic & - & Esteem builder & Hope \\
\hline & Woo & - & Personalisation & Humour \\
\hline & - & - & Persuasion & Religiousness \\
\hline & - & - & Rapport builder & - \\
\hline & - & - & Relationship deepener & - \\
\hline
\end{tabular}

VIA, values in action inventory.

FIGURE 1: Comparison of strengths measurement instrument themes.

efficient, organised and thorough can be linked to the fivefactor personality trait of 'conscientiousness' and its facets of competence, order, dutifulness, achievement striving and selfdiscipline (Carr, 2004). Furthermore, studies on the relationship between global personality factors and psychological strengths have found lower levels of neuroticism-anxiety on personality and aggression-hostility on temperament to be associated with higher levels of resilience and character strengths (Hutchinson, Stuart, \& Pretorius 2010). An alternate definition of strengths by Goodman et al. (2019) is that they are dispositional qualities that people possess to enhance their well-being. Apart from their conceptualisation, other confounding issues surrounding strengths are whether to represent them based on their adaptiveness or functionality, whether subjective or objective measurement is appropriate, if specific value or ethics systems should be consulted, or which stakeholder perceptions of change should be used. In addition, unlike the psychological pathology model where the direction of improvement or progression is known as the state of normal functioning, determining the direction or 'prognosis' of a strength is a greater challenge (Aspinwall \& Staudinger, 2003). Assessment of strengths is currently approached using quantitative questionnaires that generate a list of 'top strengths', but do not provide information about the way that these strengths interact with one another and how they then translate into behaviour is hardly known (Biswas-Diener et al. 2011). The constellation of strengths drawn from one individual would differ from another and even strengths within a constellation may appear to contradict each other (e.g. consistency vs. adaptability). A promising model of strengths and healthy psychological growth has been proposed by Snyder and Lopez (2004) to explain how the concepts of strengths, healthy processes and fulfilments interplay to promote the 'good life'. According to the model, each individual possesses a unique set of strengths which serve the achievement of optimal mental health and personal fulfilment. South African studies on psychological strengths are still sparse. A correlational study was conducted between the personality types of the Myers-Briggs Type Indicator (MBTI) 
and the factors of the Strengthscope (Taylor \& Morgan, 2015), and an instrument measuring the perceived organisational support for strength use (POSSU) was developed by Keenan and Mostert (2013). To date there have been no strengths-based instruments designed and developed for South Africa. A qualitative doctoral study of psychological strengths of public servants attending an employee assistance programme revealed some psychological strengths similar to those measured on quantitative strengths questionnaires, including having faith in self and others, quality connections with others, insight, self-regulation and self-control, hope, openmindedness, optimism, commitment, courage, accepting oneself and persistence (Ndhlovu, 2010). Thus far, academic literature on psychological strengths in relation to leadership and gender is lacking and may hold value in enabling performance and well-being in support of transformational legislation which aims to enhance representativity of previously disadvantaged women in the workplace.

\section{Muslim women and leadership in South Africa}

As a South African Muslim woman, it is an observation of the researcher that Muslim women are infrequently found in leadership positions in organisations, but there is a lack of national official or academic documented employment data to substantiate this. Conservative cultural conditioning, international Islamophobia (Terman, 2017) and South Africa's history of racial and gender discrimination suggest that Muslim women arising as workplace leaders may be somewhat challenging. Although South Africa is a secular country, organisations' operational requirements may precede religious practices, typically with minority nonChristian groups (Carrim, 2015). Corporate cultures embedded with Western norms may also be intolerant of minority religions and hold non-practising Muslim employees as a benchmark for compliance rather than be flexible with those who are religiously practising. Also, corporate dress codes may or may not be accommodating of more conservative attire for Muslim women and donning of a headscarf 'hijab', provide for halal meals and allow the observation of prayer times. In workplaces where promotions are dependent on socialising with more senior levels of management, also known as 'old boys clubs', Muslim employees are likely to be disadvantaged particularly if such events involve the consumption of alcohol. Furthermore, practising Muslim women may choose to refrain from establishing close relationships with senior male colleagues to get ahead in their careers (Carrim, 2017). Career progression of women in South Africa, regardless of religious affiliation, can be challenged because of a variety of factors such as patriarchy, education, work-life balance (April, Dreyer, \& Blass 2007), organisational structures and cultural, racial, gender, family and personal belief systems as well as prejudice, stereotyping (Damons, 2009; Łaba, 2011) and bullying (Leo \& Reid, 2013). These could compound the extent of the challenges encountered by Muslim women in the workplace and demand greater levels of resilience and adaptability to advance in leadership roles.

\section{Research purpose and objectives}

Given the dearth of South African research on psychological strengths, the purpose of this study was to explore the positive psychological strengths represented in a specific South African leadership context. The contributions of the study are intended to be both theoretical and practical. South African research on the implementation of positive psychological concepts at work is still sparse, and this study is an effort to contribute to the growing 'global' body of positive psychological research and practice in relation to leadership. From a practical workplace perspective, the study examines the positive psychological factors that Muslim women perceive to be supportive of their successful leadership in the workplace. The qualitative research objective of the study was therefore to explore the psychological strengths manifested by Muslim women who occupy leadership roles in the workplace.

\section{Research design}

\section{Research approach}

The research methodology selected for the study is a qualitative approach.

\section{Research strategy and method}

Semi-structured interviews were used to derive the psychological strengths of participants. The guidelines for the IPA (Smith, 2004) qualitative method were applied in this study, which prescribes a minimal number of interview questions and purposive sampling.

\section{Research participants and sampling}

The criteria for establishing a purposive sample had to be based on knowledge of the population being studied, its elements and the purpose of the study (Palinkas et al., 2015) and these were stipulated as being a Muslim women and having experience in a leadership role or senior management. To identify Muslim women leaders, professional South African Muslim boards were approached for referrals and these organisations included the Islamic Medical Association, the Minara Chamber of Commerce and the Institute for Learning and Motivation. Rather than drawing a random sample, email invitations stating the criteria were extended to all the referrals of which 15 participants consented to participate, whose residential locations included Durban, Pietermaritzburg and Johannesburg.

\section{Description of participants}

Many of the participants held positions where they functioned in more than one industry or held dual or multiple roles. Collectively, the participants held occupations in the healthcare industry (public and private), textile and hospitality industries, higher education, financial institutions, media and communications and a non-governmental organisation (NGO). Positions they held included those of 
manager, director, university dean, senior lecturer, activist, head of department, head of hospital unit and chief executive officer (CEO). Fourteen of the participants were Indian Muslims (93\%) and one participant was a white Muslim (7\%). An overview of the age, qualifications and family status of the research participants is presented in Table 1.

\section{Data collection methods}

Individual participants were interviewed at their places of work and the semi-structured interviews conducted elicited responses on the leadership and strengths experiences of the participants. Participants were provided with the same standard set of questions which enquired what their leadership roles entailed, what challenges they experienced as leaders and the strengths employed in these cases as well as opportunities encountered and the strengths employed in these instances. The interviews were audio recorded, with participant consent, and thereafter transcribed verbatim.

\section{Data recording and analysis}

Transcriptions of the interviews were analysed according to the recommended guidelines of IPA. The approach aims to assimilate a complete understanding of a participant's lived experience, by engaging in a double hermeneutic of understanding the participant's understanding of their experience and recording these observations (Smith, 2004). Practically, this was done by listening to the participants as they were being audio-recorded, reflecting this understanding to them by paraphrasing and summarising comments back to the participant for confirmation. For example, the following participant statement was responded to by the interviewer 'having a mentor opened doors for you?' as a reflective question to probe an issue further:

'[I]t was very difficult to get into a management position, because if it was between me and a colleague and the colleague was male, then the male got it. That's what I have realised. If it was female versus female then it was easier to get in there. So it was a huge struggle getting into a management role because everyone wants

TABLE 1: Descriptive overview of participants.

\begin{tabular}{lclll}
\hline Participant & Age & Highest qualification & Marital status & Children \\
\hline 12 & 33 & Matric (A levels, United Kingdom) & Married & Yes \\
1 & 37 & BSc, MBA & Married & Yes \\
8 & 38 & Masters (current) & Single & Yes \\
14 & 38 & $\begin{array}{l}\text { Medical degree, Master's Actuarial } \\
\text { Science, PhD }\end{array}$ & Married & Yes \\
3 & 39 & Medical degree, current PhD & Married & Yes \\
11 & 39 & Matric & Single & Yes \\
15 & 39 & BA, Postgraduate diploma & Single & Yes \\
2 & 41 & PhD & Single & No \\
5 & 43 & Bcompt & Single & Yes \\
6 & 44 & Masters degrees (medical) & Single & No \\
10 & 46 & Medical degree, PhD & Married & Yes, adult \\
4 & 50 & BA Hons & Married & Yes, adult \\
14 & 55 & Education degree, MBA (current) & Married & Yes, adult \\
9 & 67 & Medical degree, PhD & Married & No \\
7 & 68 & Medical degree, PhD & Married & Yes, adult \\
\hline
\end{tabular}

BSc, Bachelor of Science; MBA, Master of Business Administration; BA, Bachelor of Arts. management experience and unless you found a mentor that was willing to give you the opportunity to get into the role or someone who saw your potential.' (Participant X/Alias, gender, age/profession/grade)

Intermittently, short reflective statements were used by the interviewer to check that the understanding was clear, without disrupting the flow of the participant's narration.

Following the interview, the researcher was required to engage with and interpret the transcript according to four prescribed steps: initial case analysis, connecting and clustering the themes, continuing analysis of other cases and master table of themes, and writing up results (Smith, 2004). The characteristic features of IPA are consistent with the aims of this research, namely, idiographic, inductive and interrogative, because individual cases were studied until closure was achieved on all conceptual themes from the raw results. This was done before moving on to the next case, with comparisons of convergence and divergence of themes subsequently being done between the participants' arising themes. Being idiographic, an intense study of the individual was done, and being inductive involved condensing raw data into summative descriptions or concepts which were then linked (Smith, 2011). A total of 28 sub-themes were derived from the analysis of the interview data and these reflected strengths which were not subject to strict predefining criteria, but rather were accepted as those positive cognitive or affective characteristics, coping resources or values that participants conveyed as meaningful to them in enabling their progress or overcoming difficult situations in their interviews. Conceptually similar strengths were categorised as themes and recorded as cognitive, emotional, interpersonal, values or motives and behavioural strengths for easier reference. The method allows for the emergence of unanticipated themes during analysis. In addition, as an interrogative method (Smith, 2011), the results of the analysis are evaluated for their confirmation or contrast against empirical literature. This is elaborated on in the discussion of the results.

\section{Role of the researcher and strategies to ensure data quality and integrity}

Using an idiographic research approach like IPA assists to understand individual experiences in-depth (Smith, 2017). Being suitable for applied psychology research (Hefferon \& Gill-Rodriguez, 2011), IPA is concerned with meaningmaking on the part of both participant and researcher and examines people's perceptions of major experiences that happen to them and elicit a reflective cognitive response and emotions related to the experience. The reflective sense and meaning-making is shared with the interviewing researcher who, in turn, interprets the participant's interpretation of an experience (Smith, 2018). This allows for the researcher to understand the experiences of the research participants from their own perceptions of their leadership experiences and the strengths they applied in those contexts. During the interview the researcher simultaneously analyses while collecting 
information during the interview process itself and the interviewer is accountable for the context that the questions provide for the interviewee's responses (Klenke, 2008). The role of the researcher as interviewer is to make sense of and capture the psychological world of the participant, belief systems and perceptions, the content, and the complexity of the meanings created about these (Smith, 2004). Themes are captured from the sequential process of initial case analysis, clustering of the themes, continuing analysis of other cases and repeating the process through to a master table of themes, and writing up of the results (Smith, 2004). Both the interviewing process and data analysis require attentiveness and consistency on the part of the researcher to maintain the credibility and reliability of the resulting themes.

\section{Ethical considerations}

This article followed all ethical standards for qualitative research involving the interviewing of human subjects, particularly the protection of confidentiality.

\section{Results}

Excerpts from the 15 participant transcripts (P1-P15) follow, with the derived sub-themes being in support of the strengths constructs.

\section{Theme 1: Cognitive strengths}

Participants narrated strengths related to thinking and problem-solving and the variations as sub-themes included innovation, learning, strategic thinking, insight, resourcefulness, complex problem-solving and judgement.

Innovation was regarded as re-inventing the way that something is done (P7), identifying obstacles and limitations and using technology to change how things are done for more positive results and remaining relevant and ahead of competition (P12). Change and development were viewed as important to benefit future generations (P13):

'I always looked at how you could improve the service and how you could change the attitudes of people.' (P7)

'I have always had the ability to sort of identify what the obstacles are and then problem solve and see how we can get around it and sort of utilising innovation and technology to break those barriers and take the company forward. So that for me will be the positive issue or aspect.' (P12)

'I'm not looking for a fat salary, I don't need it. I'm not looking for a title because it doesn't really excite me at all. I'm looking for innovation, I'm looking for development, I'm looking for change.' (P13)

'Women are far more invested in the success and the strength of the future generations because as a mother that is what you want, you want a better future for your children, no matter where you sit in this world, or in society, no matter what religion, all mothers want the same thing. They've been through hardships themselves, they've had to sacrifice, they've had to suffer and it's just natural that they want better for their children. And I think that is a root desire.'
Learning was described as the ability to open the mind to other possibilities, ideas and experiences (P2), an openness to making mistakes and learning from them (P4), and being a life-long learner (P10):

'The capacity to open your mind to other possibilities.' (P2)

'I'm open to new learning and I believe that if you allow others to do it they will become more responsible.' (P4)

Strategic connecting encapsulated applying a systems approach to understanding issues, identifying overlapping and interconnected information and concepts (P13), and applying strategic thinking (P15):

'Expressed a tendency to apply a systems approach to understanding how issues related to one another as 'overlaps' and to identify patterns in information and data and draw meaningful interpretations from them. She described being skilled at 'connecting different people' to unlock opportunities through their interaction and sharing of ideas.' (P13)

"'Strategic thinking" was regarded by Participant 15 as a strength that 'anyone could develop.' (P15)

Resourcefulness describes coming up with creative solutions when conventional knowledge or other resources are lacking (P4, P14):

'If you had to have a project tomorrow and say Syria or Palestine or Somalia or somebody needs money tomorrow, I'm telling you those women, they don't even know the strengths they have ... the women will do everything'; 'In the time he was not getting an income, how I let the food stretch, how I saved, how I didn't eat meat or the luxuries ... I used to go stand outside my father's factory at four o' clock in the morning to go and sell Turkish scarves or whatever I could do because that was when the flea market concept had just come out ... they are small kids and my husband's away overseas somewhere and I'd be standing there until 11/12 for the day, and then trying to sell whatever I can and that is my money is going to be the next week's milk and bread and keep us going. And I tried to do so many things.' (P4)

'This participant emphasised the need to be resourceful in the area and to be able to come up with solutions quickly in order to deal with the problems related to poverty in the area where she taught.' (P14)

Insight was explained as the recognition of individual differences and patterns in behaviour (P7), as well as being able to analyse the core issues that have an impact on business and behaviours by being intuitively attentive to what is happening inside and outside the organisation (P12):

'In her understanding, people are different, 'there are so many types of people so you just have to deal with different types of people and see how it goes' by communicating with them at a level they relate to.' (P7)

'Getting feedback from everybody, clients, from employees' from suppliers, you know. So I think that listening and being attentive to where you are as a business. That's one of the most vital things because if you don't listen, you won't know how to take your company forward. You, you going to quickly become stale or you going to become irrelevant or the competition is going to be one step ahead of you.' (P12) 
Problem-solving was regarded as the ability to deconstruct and resolving complex problems by analysing and negotiating various elements and coming to relevant solutions (P13):

'A whole lot of different conflicting forces in our economy and that has direct impact on healthcare. And I really think that it's quite a complicated interesting environment. And as complicated as it is, it's always exciting because there's such huge challenges in it, so that's what really drove me towards, always working towards the most difficult and most complicated place I could be.' (P13)

Judgement/balanced decision-making involved being able to make decisions by being compassionate and considerate of other people, yet also able to make tougher business decisions, suggested a balanced approach (P14):

'And I think my entire nature is that I'm ruled by my heart, and not my head, I'm ruled by my heart most of the time, I do, I'm a tough decision-maker when it comes to financial etiquette in a business, strategies to save money, strategies to keep the business afloat. I'm very clear there when it comes to the business side.' (P14)

\section{Theme 2: Emotional strengths}

Emotional strengths related by the participants included perseverance (also described as commitment/determination); there were concepts related to self-confidence, adaptability, courage, independence, compassion, discipline and humour.

Perseverance as a sub-theme involved participants patiently persisting at a cause despite the obstacles encountered (P4, P15), remaining determined and working hard at realising opportunities (P6, P7). It was also described as showing commitment to a chosen path and committing oneself for the long term (P14):

'I think determination is one of the very important skills if you want to be a leader, constantly pushing, persevering, uh, you have to be very patient, you have to be tolerant.' (P4)

'Perseverance was described as 'standing by something believed to be true even when confronted by disagreement.' (P15)

'This participant stated that it was necessary to be 'persistent' and maintain a 'sense of self-worth'.' (P9)

'This participant demonstrates determination by 'working extremely hard', 'being clear' about what she wants and 'seizing opportunities' that arise.' (P6)

'So as more people will try and block or say something unpleasant, the more determined I became that I will overcome it. I didn't let it crush me. I always tell (the same to) so many girls that come to talk to me.' (P7)

'To keep leadership going, you must be in it for the long run. You must be in there to stay. You can't say that today I want to do this and then tomorrow you're not endorsing that.' (P14)

Confidence The participants made reference to confidence by having a sense of conviction and certainty about their decisions (P5), acknowledging their self-worth and upholding personal rights $(\mathrm{P} 1, \mathrm{P} 6,14)$, demonstrating assertiveness (P6), self-awareness and acceptance and valuing personal strengths (P4), and being assured about personal actions so that others would be comfortable to reciprocate with their trust and support $(\mathrm{P} 11,15)$ :

'You got to know where you need to be ... if you have contradictions within yourself you not going to be a good leader so you need to know exactly what it is, where you want to be, you need to be very clear on your policies, your procedures, your goals, who you are ... people cannot see contradiction in you.' (P5)

'The participant changed her stance from 'there was one staff who sort of, she wanted to be the person in charge and yet I knew that wasn't her role, that was my role but at that time I sort of allowed it', 'need to fit in and please everyone', to a kind of metamorphosis as she describes having 'come sort of, not full circle, but I'm almost there', 'Internally I've overcome those challenges', 'I have got more confidence in myself, realise that this is who I am, this is what I have to offer... even career-wise, if you can't appreciate or value it then I don't want to be part of your system', 'I've realised that you've got to stay true to yourself and if you stay true to yourself people will value you for who you are.' (P1)

'This participant explained that it became easier to assert herself as she progressed to more senior roles. In her own working environment, assertiveness was considered a 'masculine trait.' (P6)

'You must know two years had gone, some say grief takes two years. So I had gone through the processes of you know the whole five processes. And I had come to the realisation that it's my life, and whatever I did now is for me, not for him, not for anybody else, it's for me. And I'm also an important person, who's worthy and there's value attached to me and it wasn't now sacrificing for everybody else and mostly for him, which I did do.' (P4)

'It needs to be apparent to others that a leader has confidence in order to gain their trust and support 'your staff look to you if you display confidence, when you stand up to do a presentation and if you're not really clued up or you're not really good at it, there's no confidence at all. And when you've got self-confidence and when you display those characters you also gain a lot of trust, your colleagues and everybody else.' (P11)

'The participant referred to being confident that the effort put into a task was sufficient and the quality of the end result was of a good standard and not 'requiring assurance or validation by someone else'. In order to gain respect and be listened to in a male-dominated environment, displaying social confidence and maintaining one's presence, the participant stated 'You have to have this commanding presence and I don't mean by shouting at everybody or being rude. You have to tell them what you want, why you want it and you have to be clear to do it with a firm voice.' (P15)

Adaptability was conveyed as the ability to reframe negative situations positively and build on the positive aspects (P7, P4), to adjust her behavioural approach to different audiences (P5), apply new learning to changing circumstances (P3) and adopt a flexible approach to meeting varying demands as contexts change (P11):

'The participant described adopting a change in perception and to focus in a positive, constructive way: 'You realise it's a tough life to live but you just make yourself strong and you carry on. And you carry on with what's your important things in your life. 
So you focus back on your studies, you focus back on your work, you focus back on your ibadat [prayer].' (P4)

'When criticised or having to deal with negative attitudes, she would ignore and deflect anything negative, not take it to heart and regard such information as a projection of the other person, 'I just ignored everybody who was negative, I dismissed the negative comments, and I didn't hold it against the person. I treated them like I treated everyone else and said look, they have to learn and it's their problem and not mine.' (P7)

'When dealing with people at the same level of authority the participant approaches them with 'a much harder masculine leadership style', particularly if her authority is threatened. At a staff level she adapted with a much more 'people-oriented' approach and her staff seem to be particularly receptive and responsive to her leadership style. Again, she adapted to a 'softer, motherly and feminine role' when interacting with her children at home.' (P5)

'Adaptability was described as the ability to 'adjust positively to changing circumstances and apply new learning.' (P3)

'According to the participant, there needs to be some flexibility in approach in order to balance and accommodate both religious and work responsibilities. Her work environment enables and allows her to observe fasting and her prayers so in return, she makes herself available and still attends meetings and dinners that may extend beyond normal work hours.' (P11)

Courage was narrated as being able to motivate oneself despite the fear of adverse consequences (P2, P9), and being able to maintain integrity in spite of the fear of persecution for doing so (P13):

'You encounter the might of big corporates and they are then basically trying to bring you down to size and you then know you've got to rethink your strategy and motivate yourself to keep on going.' (P2)

Independence was considered by a participant to be linked to personal accountability for independent actions (P4), maintaining personal principles even if they differed from the social context (P6) and being comfortable with making decisions without assistance from others (P15):

'So that is now how I have looked at my journey, my journey is straight towards Allah (God). I came into this world alone and I'm going to leave this world alone. Nobody is going to be with me. And then I will have to face Allah one day. So now my destination is Him, my journey here and everything I do now is for Him.' (P4)

'The participant explained that not being able to make independent decisions filtered into relationships in the workplace and her case differed from her observations of others 'I have been on my own now for about fifteen, sixteen years and I have always made the decisions whether it was about having a child, work, moving, buying a car or buying a house I made those decisions. I didn't have to look at my husband for guidance or approval and that kind of rolled out to my work as well.' (P15)

Compassion translated as being considerate towards others over personal ambitions (P9, P13) and caring for and showing interested in the welfare of people (P14):
'I think women have more compassion and as doctors, make excellent doctors ... I think in general women have a great inner strength, not super-ambitious as men are ... you know it's a female characteristic to be fair in your dealings and be honest. Because you're not super-ambitious, you're not going to step on other people's toes to reach where you want to be.' (P9)

'I felt that as a clinician, yes we can provide brilliant care, but we just scratching the surface, we not actually changing the root of the problem, and that's what drove me towards economics ... I wanted to understand. And you know with healthcare the hardest part for many people is when they are encountered with a disease or their children are and most people are 'can we actually afford this treatment?.' (P13)

'I think my leadership style is very, very compassionate. I'm a compassionate leader and I think my entire nature is that I'm ruled by my heart, and not my head ..., I'm always loved people that I work with and I try to find that connection with them so that I'm able to lead from within and not from outside and people will only accept your leadership if you are trusting and I love that trust to be created, whether it's a beggar or whether it's somebody that doesn't have', 'I think that women care for everybody. And that's a difference you know, that's a difference in terms of the gender. Men make good leaders but women, a woman leader takes it a little further and that makes them special and remembered.' (P14)

Discipline suggests that strict personal and religious standards are applied by the participant, not willing to compromise on values (P6), and the exercise of self-control and applying principles consistently (P9):

'There is (pressure to conform) but you need to stand your ground; 'I don't attend because firstly it's in the evening, and sort of the main reason they have it, is so that they can have a drink. So I was asked by a few reps, why don't I come, so I said to them that, you know that's not my lifestyle, I mean I am not coming there for a drink and I have other means of getting educational updates, so it's not an absolute for me to come. So, when they invite me to present, then I will go and present, but I don't stay ...' (P6)

'You know we have to be disciplined to follow the rituals of our prayers and I think that the five pillars are so important in Islam and nothing about Islam is unjust or something that you can't do or difficult to do, it's in the capability of all humans to do the basic requirements for Islam.' (P9)

Humour was put forward by a single participant, as being able to view issues less seriously, discuss them in a lighthearted manner, de-personalise and reflect on events jokingly (P7):

'The participant commented that life could not be taken too seriously and being able to depersonalise and laugh about an event helped to put it behind her; 'A gentle no got them sorted out [Laughs]. You must see the funny side of life as well.' (P7)

\section{Theme 3: Interpersonal strengths}

Interpersonal strengths were those positive characteristics presented by the participants that enabled their relationships with others, including the sub-themes of building and managing relationships, diversity, persuasiveness, community and empowering others. 
Building relationships was described through exhibiting warmth, friendliness and showing others that they are valued (P5), being able to communicate with people at their level by applying empathy (P8, P10, P14), building strategic relationships with key stakeholders (P11) and maintaining strategic alliances (P13):

'... When they went to vote I told them everything, I told them about my Granny ... and they laughed at me and I said now go in for the referendum and freakin' go and vote yes. And they all came back and said they voted yes ... because we love you so much and you broke our heart with your stories.' (P5)

'Yeah, so I think that a leader should be a peoples' person, and not up there and somebody who people are afraid of but someone who they feel they can come and talk to but they can also have an element of respect for them. They know, you know what, she is leader and we need to respect the particular terms of the contract by which we are bound to whatever it is she is leading, uhm but by the same token she's our sister, she's our friend and we can talk to her.' (P8)

'I prefer to hold the hands of people, they are some very nice leaderships sayings like, you either move up pulling people up or stepping on people, so I prefer to pull people up.' (P10)

'Maintaining relationships with these stakeholders is multifaceted and complex', 'I mean it's a huge thing it's very complicated, involves complicated relationships with the doctors, with the professionals, it's a financially very complicated system and socially and politically it's also quite an important system.' (P13)

Embracing diversity was defined by being able to co-exist and accept others who may be different (P2), treating people equally regardless of their background (P10), transcending barriers such as ideologies, race, age, economic status, culture and relating to individuals (P8), and challenging and resolving stereotypes (P12):

'This is something that you know I found out about very early on because we lived in a society that was very segregated and so you didn't get to meet people from other groups ... you're so closed off and conditioned (to discriminate).' (P2)

'Being a South African Muslim woman and being a leader, you have to know how to break down barriers because there are a lot of them in our community, whether it's between women in parda and women in hijab or women in hijab and women who don't wear hijab or black people and white people or white people and Indian people or, there are so many barriers, ideological, racial, incomebased, age-based, and in order to break down these barriers you need to be a very understanding person, you need to have a lot of empathy, you have to have a good listening ear, you've got to be kind, you've got to be just, you've got to be non-oppressive... but you also have to be firm and you have to be accountable and you always need to hear both sides the story as well (fair) and you always have to really think things through.' (P8)

Persuasion strengths related to being able to negotiate terms with other stakeholders, motivate others to accept a personal point of view or preferences (P6, P10), guiding others to apply their own strengths (P7); conveying ideas and giving direction to others, gaining their buy-in and boosting morale (P11):
'When having to negotiate terms at work, it helps to have a persuasive approach, particularly when having to deal with senior members of the organisational hierarchy. She also had to persuade her parents to allow her to continue with studies in medicine and overseas.' (P6)

'She used a gentle approach to guide their actions by conveying information in a kind rather than authoritative manner, highlighting what they had done well and suggesting areas that they could improve upon. Wording her messages positively also made it easier for her to gain buy-in and acceptance; 'I get their buy-in all the time, I think it's being kind. I think they are young people who are struggling to do this work, they are battling in difficult circumstances and we have to see through all that.' (P7)

'Her staff is cohesive as a group and she stated that she gains their buy-in and support by motivating the benefits of a course of action rather than directing others.' (P10)

'She found it important to be able to relate strategic ideas to others and give direction to the team, as well as communicate to gain team buy-in and boost morale. In the home context, she favoured negotiation skills for defining commitments and responsibilities with partners.' (P11)

Community collaboration was described as viewing people and the events between them as interconnected, identifying that the purpose of human beings is to help one another to benefit collectively (P1), collaborating with others as part of a greater whole, fostering a sense of togetherness, and having individual actions an impact on the whole, improving conditions for others (P13) and enabling the development of the greater community (P14):

'Participant conveyed that people and events are related and inter-connected recurred 'I think our purpose is to serve others and to benefit others and in that way we benefit ourselves.' (P1)

'It's the commitment to sort of, collaborate to a oneness. And to understand that people can do bad things and they might get away with it, they actually might succeed. But at the end of the day you defeating yourself because there is a sense of oneness, there is a sense of we are all here together, if we could only see it.' (P13)

Empowerment is the strength of enabling others with knowledge, skills and resources, and respecting them as capable of helping themselves to improve (P10). The need to elevate the status of others was rooted in the struggles of in her own background (P14):

'She came from 'a very poor background and I always feel for the poor. So that passion, that commitment, that selflessness and I think that genuine love ...' (P14)

\section{Theme 4: Values strengths}

Values and motivational strengths as a theme related to integrity and having a sense of purpose, taking initiative focussing on achieving excellence. Participants were mindful of applying justice and being respectful and authenticity was raised by a single participant.

Integrity arose on sub-themes of honesty and transparency when exercising judgement (P3, P9), maintaining ethical relationships with staff and stakeholders without 
discrimination (P8), applying ethics and Islamic principles personally and in one's organisation (P10) and by being conscious of and standing up for what is right (P13):

'The most important thing is communication in our field', 'You have to be absolutely fair and transparent because whenever you do things as a leader, if it's questioned you must be able to justify it properly and I think that's extremely important for me in leadership, is transparency and fairness in everything.' (P3)

'Participant 8's values of non-discrimination and promoting Islam through the organisation as a universal religion rather than reserved for Indians. The exposure to Tariq Ramadaan's lectures on ethics influenced her employment practices and the appointment of staff was 'strategic', as she deliberately employed a multiracial staff complement in order to 'demonopolise Islam' and recognises her staff for their merits rather than the colour of their skin.' (P8)

'People are not fools, they may succumb to leadership because they may be afraid of leadership but they will never be truly motivated by a leader who is not consistent and who doesn't display integrity ... If you look at the great leaders of our times, the one thing that has always come first is their integrity, their consistency. The fact that they are one person, whether they sitting with government, with private sector or labour, they carry the same voice and I'm thinking of Mandela because he's the greatest example of integrity so that I think is a male and a female thing, and it's not to say that most leaders don't have integrity, but integrity needs to be backed up with courage and that is what a lot of our leaders lack, a lot of our leaders are scared to live their integrity because they fear that they will be persecuted or they will not be allowed to grow on their path of growth if they are courageous and they stand strong to their integrity.' (P13)

Purpose was evident in the participants' sense of contributing to a greater good and serving society $(\mathrm{P} 1, \mathrm{P} 4)$, pursuing a career that cultivates a passion (P8, P14) and being driven to make a difference in a subject one is passionate about (P10, P13):

'The purpose of people is to serve and benefit others.' (P1)

'The participant's significant passion was writing and she decided to abandon university studies after completing her first year very successfully in favour of a Technikon diploma in journalism. 'And it was not seen as being, you know politically correct if I can use that term, if you got an A aggregate to go to Tech. So there was kind of subtle pressure not from my immediate family but from within myself and society to go the University route as opposed to the Tech route.' (P8)

'You got to innately believe and love what you doing and then you will be a good leader', 'You got to believe as a leader, whether it's a leader in the community that I' $m$ in, whether it's a leader of that I'm doing a programme with women, or it's a talk or whether it's a financial seminar I'm involved with. If those things you don't have the passion for, those things you [are] never going to be a good leader [at] and that's my strength.' (P14)

'I think academia was the place to be irrespective of that fact that if I was in private or public professional practice the salary would have been much higher. I love what I do and sometimes I can't wait to get to work, so it's great here.' (P10)

'Sometimes you don't decide what your passion is but you are given a passion. And you can either ignore it or you can follow it. And I think that force, that passion was so strong within me that it almost, it overcame the negativity, the doubt, I mean the doubt and uncertainty did get me down a lot of times but there was that constant push internal push ... constant desire to push forward and that was quite powerful.' (P13)

Initiative was described as identifying and acting on opportunities (P1, P2, P15), making a motivated and conscious effort to achieve goals (P2, P7) and acting to effect improvements (P9):

'So I approached the directors and put in a proposal and we setting up an optometry practice in the next six months.' (P1)

'Those times we were engaging in these different struggles and how lonely it actually was and this was say like fifteen, twenty years ago. So, a lot has changed since then ... the paths have in a sense been created to enable younger Muslim women to get into those spaces because others have done it and gone there ... but we need more, that's the issue.' (P2)

'You need to develop that passion and that only comes from doing it yourself because no one is going to come and do that for you. So, I find that many women who perhaps are interested, they don't necessarily make as much effort as they could ... What I think tends to happen ... once women, Muslim women in particular, marry, there's this sense that they've got to deal with ... the family home and domestic commitments they have to deal with and extended family situation and so on.' (P2)

'The training programmes she implemented in hospitals early in her career, paved the way for greater research and development and led to her expertise in her field: 'You initiate something and you find it is successful. For example, I initiated teaching of [staff] in the [hospital] and I found it to work very, very well.' (P7)

'Showing initiative by creating a syllabus for herself and others, when she found that this was lacking. Compiling the syllabus made a significant contribution to her speciality in her field.' (P9)

Excellence was described as the achievement of best results (P9, P10) and contributing a high standard of performance (P1, P9, P11):

' $[B]$ because of the work I delivered and the success rate of the students I was allocated, every semester there was an increase in the number of students they were allocating to me ...', 'I built the clinic, it's good motivation, that even my boss said 'When you were here you did a good job.' (P1)

'Consistently achieved top grades in her studies.' (P9)

'Much of the successful changes that Participant 11 had put into place were because of the fact that she was 'driven to perform' and had 'direction', expressing pride in her achievements.' (P11)

Respect was described as showing humility by relating to others at their level without feeling self-important, having non-judgemental regard for people as human beings, as well as self-respect (P2, P7):

'A leader should be a 'regular person' who is able to relate to others at the same level.' (P2)

'Basic respect for other individuals as human beings, not judging them for their opinions even if these were negatively directed at her, having respect for people's ability and capability and respect for her patients were derived from her responses. Self-respect was also evident, as she recognised her own value and stood by her principles when challenged.' (P7) 
Justice was defined as dealing with people with fairness and equality (P8, P9):

'Justice and equality were promoted over an organisational hierarchy and Participant 8 was conscious and careful about the type of language used to communicate with employees so that they would not perceive differences between each other and encouraged working together rather than underneath each other.' (P8)

'This participant emphasised the quality of justice, as 'staff must not see you as being unjust then you will never get their cooperation'; 'Islam teaches you to be just and [in] my role as a leader I was just in all my undertakings, so that helped.' (P9)

Authenticity was expressed as being true to oneself, accepting the positive and negative aspects of oneself, being transparent about views and appraisals of issues and acting consistently with these, as well as the exploration and living of personal potential (P1, P10):

'Very important to be true to yourself and lies in the end will just lead to negative repercussions. So, I think it's very important to be true to yourself and being positive about who you are and not trying to fit someone else's shoes.' (P1)

\section{Theme 5: Behavioural strength}

Self-management describes a single strength category related to being organised and able to multi-task (P4, P10, P11, P14), clearly defining goals and working in a structured manner to achieve them (P6) and the importance of being able to apply effective time management, prioritisation and delegation (P8). From the interview responses, self-management was mentioned as necessary to deal with the major difficulty of maintaining a balance between work and family life responsibilities:

'Coordinate multiple activities.' (P10)

'If you're not organised, you're not a leader.' (P11)

'So I say women can multi-task and I don't think that women are using all of their facets that they could. Or we also become very complacent in this role.' (P14)

'I used to do everything for the organisation initially, the marketing, the admin, the fundraising, everything, and it took its toll on me because as a mother I found that I didn't have time to do a lot of things and also I didn't have the time to make enough money to sustain myself because I felt uncomfortable about taking ... So essentially, I'm director, I'm also trustee and I'm the founding member right, and basically currently my roles have evolved so as I take on new staff my roles become reduced.' (P8)

\section{Discussion}

The objective of this study was to explore the psychological strengths of Muslim women in leadership roles in the workplace. With regard to the broader categories as themes, the emotional strengths sub-themes occurred most frequently between the participants, followed by values or motivational strengths (29 and 27 interview references to these sub-themes, respectively). Individual sub-themes that featured more prominently in frequency between the participants were confidence, building relationships, having a sense of purpose, initiative and self-management. These would therefore appear as the strengths considered to be more important to Muslim women leaders, in a South African context.

All of the derived cognitive strengths except insight were in common with either the VIA, Strengthscope, Realise 2 or StrengthsFinder definitions. Wen, Butler and Koutstaal (2012) defined 'insight' as applicable to problems that were illdefined and the solver would adaptively restructure the problem, reset the goal state and search processes to reach a new goal state. This occurs through a process of meaningmaking, appraisal and revision of a situation and interpreting it to discern the significance.

Similar to the emotional strengths, each of the subthemes could be compared with psychological strengths found on existing quantitative measures (Figure 1). These strengths also concur with a South African doctoral study which identified persistence, perseverance and assertiveness, together with strong interpersonal communication skills, to be useful in navigating barriers to women's advancement and potential sources of stress such as family responsibility and gender issues (Zulu, 2007). In addition, a Chinese study linked higher levels of emotional strengths to greater life satisfaction (Chan, 2009).

The interpersonal strengths of this study complement previous studies of women leaders which yielded negotiation and persuasion skills based on engagement and genuine understanding (Greenberg \& Sweeney, 2005), applying an inclusive and team-oriented approach, showing a willingness to take risks (Caliper, 2014), communicating directly and valuing relationships (April \& Dreyer, 2007). They also alluded to being authentic, kind, embracing the diversity of others and encouraging equality, and being compassionate and cooperative (Caliper, 2014).

Beyond the cognitive, emotional and interpersonal abilities identified as strengths, the participants also conveyed personal values which they reported to live by, and apply. The strength of having a sense of purpose and being passionate about a particular cause or activity was not represented with the quantitative strengths measures but has been alluded to in logotherapy (Frankl, 1963) and the Japanese concept of ikigai, or having a purpose in life (Garcia \& Miralles, 2016). The self-management strength in the behavioural category is somewhat different from the other characteristic-type strengths by reflecting a skill but could possibly be linked to the execution cluster of the Strengthscope which measures efficiency, flexibility and self-improvement.

An overview of the results (Table 2) suggests that many strengths may be captured using a quantitative strengths instrument, but may overlook some important context-specific strengths such as insight, purpose and self-management in this study which were convergent themes from the participants. Secondly, but not less importantly, strengths were perceived as relevant by the participants in both positive and negative 
TABLE 2: Overview of psychological strengths of Muslim women leaders.

\begin{tabular}{|c|c|c|c|c|}
\hline Cognitive & Emotional & Interpersonal & Values & Behavioural \\
\hline Innovation & Perseverance & Building relationships & Integrity & Self-management \\
\hline Learning & Confidence & Embracing diversity & Purpose & - \\
\hline Strategic connecting & Adaptability & Persuasion & Initiative & - \\
\hline Resourcefulness & Courage & Community collaboration & Excellence & - \\
\hline Insight & Independence & Empowerment & Respect & - \\
\hline Problem-solving & Compassion & - & Justice & - \\
\hline & Humour & - & - & - \\
\hline
\end{tabular}

circumstances, and the participants tended to speak of them with a long-standing conviction rather than abilities to be used on an ad hoc basis and they regarded strengths to be developable over time. Thirdly, given that women leaders in general face a number of challenges that affect their career progression, capturing the strengths of women leaders on extended South African samples may lead to a finding of some key strengths that can be applied vigorously in leadership development programmes for women. The study succeeded in exploring and generating a taxonomy of strengths which can be compared across sub-populations and quantitative measures of strengths. Furthermore, IPA interviews should be considered as a supplementary method to the more common method of questionnaires for a richer representation and understanding of psychological strengths.

\section{Limitations and recommendations}

Limitations related to the methodology of the study include that the derived strengths were fairly descriptive, but perhaps not exhaustive. It is possible that participants may have overlooked some of their individual strengths when relating their experiences as these may not have been consciously obvious to the participants. Secondly, the method of IPA calls for much smaller samples with the argument that 'less is more' and greater depth of analysis is achieved. The larger sample of this study was in line with the supervising university sample requirements for doctoral research, and it is the opinion of the researcher that because a full analysis of one case occurs before moving to the next, there is no impulsive aggregation of themes across cases and the integrity of idiographic analysis can be maintained while also generating a broader range of rich themes, by adhering to the process of IPA. Although the study contributes theoretically to psychological strengths and has practical value for leadership development, it is recommended that the study be duplicated across other subpopulations in the South African context, according to gender, cultural, religious or occupational membership, for example, to expand on and develop a theoretical understanding of contextual psychological strengths, and ultimately a local taxonomy. In response to the dilemma of classifying human strengths, it is submitted that they can, indeed, be complex and composed of personality traits, states and cognitive abilities and the results of this study did not show particular preference to any currently established strengths framework. A criticism of the strengths approach latches onto the fact that strengths may be used inappropriately, but this can be moderated by creating awareness of strengths by firstly identifying them and adjusting their use as appropriate to the context. Meta-cognitive awareness and emotional intelligence may play a positive role in moderating the application of strengths and the relationships with these constructs may be an area for further empirical investigation.

\section{Conclusion}

The objective of this study was to explore the nature of psychological strengths of a sample of leaders who are female and belong to the Islamic faith, within a South African work context. The results contribute to the field of positive psychology by providing for a taxonomy of psychological strengths which roughly fitted into the conceptual categories of cognitive strengths, emotional strengths, interpersonal strengths, values/motivational strengths and a single behavioural strength. By adopting an IPA approach, the resulting taxonomy mimicked a range of strengths that were dispersed across other established quantitative strengths measures, but not comprehensively by any one particular measure. It is highly possible that using a quantitative measure of individual strengths may fail to substantially capture a representative profile, potentially missing those relevant to the individual's personal context. Novel strengths included insight, purpose and self-management. While some strengths were narrated in relation to religious background or experiences, leadership context examples featured prominently in the descriptions of psychological strengths applied and it is anticipated that there were more strengths in common between women in leadership roles with some cultural and religious variations. The outcomes of the study suggest that the methodology of IPA succeeded in providing a comprehensive list of strengths. It would be valuable to extend the IPA approach of strengths assessment to other South African leadership populations which may reveal additional strengths and a more inclusive taxonomy could be developed to support leadership development in a diverse workplace.

\section{Acknowledgements Competing interests}

The authors declare that they have no financial or personal relationship(s) that may have inappropriately influenced them in writing this article.

\section{Authors' contributions}

F.A. was the project leader and was responsible for the project design, analysis and interpretation of results. J.H.B. made conceptual contributions and supervised the doctoral study. 


\section{Funding information}

Funding assistance from the National Research Foundation is gratefully acknowledged.

\section{Data availability statement}

Data sharing is not applicable to this article as new data that was created or analysed in this study was derived from individual interviews with personally identifiable information.

\section{Disclaimer}

The views and opinions expressed in this article are those of the authors and do not necessarily reflect the official policy or position of any affiliated agency of the authors.

\section{References}

Ahmed, R. (2008). Attitudes towards Muslim women. Unpublished Master's dissertation. Durban: University of KwaZulu-Natal.

April, K., Dreyer, S., \& Blass, E. (2007). Gender impediments to the South African boardroom. South African Journal of Labour Relations, 31(2), 51-67.

April, K.A., \& Dreyer, S. (2007). Gender unplugged in the executive boardroom, effective executive. Rondebosch: University of Cape Town.

Aspinwall, L.G., \& Staudinger, U.M. (2003). A psychology of human strengths: Some central issues of an emerging field. In L.G. Aspinwall \& U.M. Staudinger (Eds.), A psychology of human strengths: Fundamental questions and future directions for a positive psychology (pp. 9-22). Washington, DC: American Psychological Association.

Biswas-Diener, R., Kashdan, T.B. \& Minhas, G. (2011). A dynamic approach to psychological strength development and intervention. The Journal of Positive Psychology, 6(2), 106-118. https://doi.org/10.1080/17439760.2010.545429

Brook, J., \& Brewerton, P. (2006). Strengthscope technical manual. London: Strengths Partnership.

Buckingham, M., \& Clifton, D.O. (2001). Now, discover your strengths. London: Simon \& Schuster.

Caliper. (2014). Women leaders research paper (Whitepaper). Princeton, NJ: Caliper Retrieved from https://www.calipercorp.com.

Carr, A. (2004). Positive psychology: The science of happiness and human strengths. East Sussex: Brunner-Routledge.

Carrim, N.M.H. (2015). Managing religious diversity in the South African workplace. In S. Groschl \& R. Bendl (Eds.), Religious diversity in the workplace (pp. 113-136). Farnham: Grower.

Carrim, N.M.H. (2017). To be or not to be: Muslim identities in South Africa. In J. Mahadevan \& J.C. Mayer (Eds.), Islam, workplace diversity and reflexive HRM (pp. 77-94). Pretoria: Routledge.

Chan, D.W. (2009). The hierarchy of strengths: Their relationships with subjective wellbeing among Chinese teachers in Hong Kong. Teaching and Teacher Education, 25, 867-875. https://doi.org/10.1016/j.tate.2009.01.010

Clifton, D.O., \& Harter, J.K. (2003). Investing in strengths. In K.S. Cameron, B.J.E. Dutton \& C.R.E. Quinn (Eds.), Positive organisational scholarship (pp. 111-121) San Francisco, CA: Berrett-Koehler Publishers. Excerpt Chapter 8. Retrieved from https://bfeild.typepad.com/transcending_leadership/Investing $\% 20 \mathrm{in} \% 20$ Strengths.pdf.

Compton, W.C. (2005). An introduction to positive psychology. Belmont, CA Wadsworth.

Damons, M.H. (2009). The performance of female principals in the management of selected secondary schools in the Gauteng Province. Melvin Harold. Unpublished thesis. University of Johannesburg. Retrieved from https://hdl.handle.net/10210/237

Department of Labour. (1998). Employment Equity Act, No. 55 of 1998. Retrieved from https://www.labour.gov.za.

Deptula, D.P., Cohen, R., Phillipsen L.C. \& Ey, S. (2006). Expecting the best: The relation between peer optimism and social competence. The Journal of Positive Psychology, 1(3), 130-141. https://doi.org/10.1080/17439760600613685

Frankl, V.E. (1963). Man's search for meaning. New York: Simon \& Schuster.

Garcia, H., \& Miralles, F. (2016). Ikigai: The Japanese secret to a long and happy life. London: Penguin.

Goodman, F.R., Disabato, D.J., \& Kashdan, T.B. (2019). Integrating psychological strengths under the umbrella of personality science: Rethinking the definition, measurement, and modification of strengths. The Journal of Positive Psychology, 14(1), 61-67. https://doi.org/10.1080/17439760.2018.1528380

Greenberg, H., \& Sweeney, P. (2005). The qualities that distinguish women leaders. Princeton, NJ: Caliper Corp.
Harter, J.K., Schmidt, F.L., \& Hayes, T.L. (2002). Business-unit-level relationship between employee satisfaction, employee engagement, and business outcomes: A meta-analysis. Journal of Applied Psychology, 87, 268-279. https://doi. org/10.1037/0021-9010.87.2.268

Hefferon, K., \& Gil-Rodriguez, E. (2011). Interpretative phenomenological analysis. The Psychologist, 24(10), 756-759. Retrieved from https://www. thepsychologist.org.uk/archive/archive_home.cfm?volumeID=24\&editionID= thepsychologist.org.u

Hutchinson, A.K., Stuart, A.D., \& Pretorius, H.G. (2010). Biological contributions to well-being: The relationships amongst temperament, character strengths and
resilience. SA Journal of Industrial Psychology, 36(2), 1-10. https://doi. org/10.4102/sajip.v36i2.844

Kaiser, R.B., \& Overfield, D.V. (2011). Strengths, strengths overused and lop-sided leadership. Consulting Psychology Journal: Practice and Research, 63(2), 89-109. http://doi.org/10.1037/a0024470

Keenan, E.M., \& Mostert, K. (2013). Perceived organisational support for strengths use: The factorial validity and reliability of a new scale in the banking industry. SA Journal of Industrial Psychology, 39(1), 1-12. https://doi.org/10.4102/sajip.v39i1.1052

Klenke, K. (2008). Qualitative research in the study of leadership. Bingley: Emerald Group.

Łaba, K. (2011). Themes in South African studies on women in the workplace. In A. Bosch (Ed). The South African board for people practices women's report 2011 (pp. 33-37). Parktown: SABPP.

Leo, L., \& Reid, R. (2013). Gender and workplace bullying. In A. Bosch (Ed.), South African board for people practices women's report 2013 (pp. 26-30). Parktown: SABPP.

Linley, P.A., Willars, J., \& Biswas-Diener, R. (2010). The strengths book. Coventry: CAPP Press.

Macaskill, A., \& Denovan, A. (2014). Assessing psychological health: The contribution of psychological strengths. British Journal of Guidance \& Counselling, 42(3), 320-337, https://doi.org/10.1080/03069885.2014.898739

Maddi, S.R. (2006). Hardiness: The courage to grow from stresses. The Journa of Positive Psychology, 1(3), 160-168. https://doi.org/10.1080/1743976060 0619609

Ndhlovu, J.N. (2010). Exploring positive psychological strengths in employees attending EAP in the public service: A qualitative study. Doctoral dissertation. Pretoria: University of South Africa.

Palinkas, L.A., Horwitz, S.M., Green, C.A., Wisdom, J.P. Duan, N., \& Hoagwood, K. (2015). Purposeful sampling for qualitative data collection and analysis in mixed method implementation research. Administration and Policy in Mental Health and Mental Health Services Research, 42(5), 533-544. https://doi.org/10.1007/ s10488-013-0528-y

Park, N., Peterson, C., \& Seligman, M.E.P. (2006). Character strengths in fifty-four nations and the fifty US states. The Journal of Positive Psychology, 1(3), 118-129. https://doi.org/10.1080/17439760600619567

Peterson, C., \& Seligman, M.E.P. (2003). Character strengths and virtues: A handbook and classification. Washington, DC: American Psychological Association.

Rath, T. (2007). StrengthsFinder 2.0. New York: Gallup.

Seligman, M.E.P. (2011). Flourish: A visionary new understanding of happiness and well-being. New York: Simon \& Schuster.

Seligman, M.E.P., \& Csikszentmihalyi, M. (2000). Positive psychology: An introduction. American Psychologist, 55(1), 5-14. http://doi.org/10.1037/0003-066X.55.1.5

Seligman, M.E.P., Steen, T.A., Park, N., \& Peterson, C. (2005). Positive psychology progress: Empirical validation of interventions. American Psychologist, 60(5), 410-421. https://doi.org/10.1037/0003-066X.60.5.410

Smith, J.A. (2004). Reflecting on the development of interpretative phenomenological analysis and its contribution to qualitative research in psychology. Qualitative Research in Psychology, 1, 39-54. https://doi.org/10.1191/1478088704qp004oa

Smith, J.A. (2011). Evaluating the contribution of interpretative phenomenological analysis. Health Psychology Review, 5(1), 9-27. https://doi.org/10.1080/1743719 9.2010 .510659

Smith, J.A. (2017). Interpretative phenomenological analysis: Getting at lived experience. The Journal of Positive Psychology, 12(3), 303-304. https://doi.org/1 $0.1080 / 17439760.2016 .1262622$

Smith, J.A. (2018). Participants and researchers searching for meaning: Conceptual developments for interpretative phenomenological analysis. Qualitative Research in Psychology, 12(3), 303-304. https://doi.org/10.1080/14780887.2018.1540648

Snyder, C.R., \& Lopez, S.J. (2004). The future of positive psychological assessment: Making a difference. In S.J. Lopez \& C.R. Snyder (Eds.), Positive psychological assessment: A handbook of models and measures (pp. 461-468). New York: Oxford University Press.

Staudinger, U.M., \& Leipold, B. (2003). The Assessment of Wisdom-Related Performance. In S.J. Lopez \& C. R. Snyder (Eds.), Positive psychological assessment: A handbook of models and measures (pp. 171-184). Washington, DC: American Psychological Association. https://doi.org/10.1037/10612-000

Strengthscope. (2010). Strengthscope technical manual. London: Strengthscope.

Stokols, D. (2003). The ecology of human strengths. In L.G. Aspinwall \& U.M Staudinger (Eds.), A psychology of human strengths: Fundamental questions and future directions for a positive psychology (pp. 331-343). Washington, DC: American Psychological Association. https://doi.org/10.1037/10566-023 
Taylor, N., \& Morgan, B. (2015). Brief technical report on the relationship between work-related strengths and personality types. Johannesburg: JVR Psychometrics.

Terman, R. (2017). Islamophobia and media portrayals of Muslim women: A computational text analysis of US News Coverage. International Studies Quarterly, 61(3), 489-502. https://doi.org/10.1093/isq/sqx051

Van Der Westhuizen, S., De Beer, M., \& Bekwa, N. (2011). Psychological strengths as predictors of postgraduate students' academic achievement. Journal of Psychology in Africa, 21(3), 473-478.
Wen, M., Butler, L.T., \& Koutstaal, W. (2012). Improving insight and non-insight problem solving with brief interventions. British Journal of Psychology, 104(1), 97-118. https://doi.org/10.1111/j.2044-8295.2012.02107.x

Zhou, Q., Valiente, C., \& Eisenberg, N. (2003). Empathy and its measurement. In S.J. Lopez (Ed.), Positive psychological assessment: A handbook of tools and measures (pp. 269-284). Washington, DC: American Psychological Association.

Zulu, C.B. (2007). A comparative study of women in management in higher education in South Africa and the United Kingdom. Doctoral thesis. Pretoria: University of South Africa. 